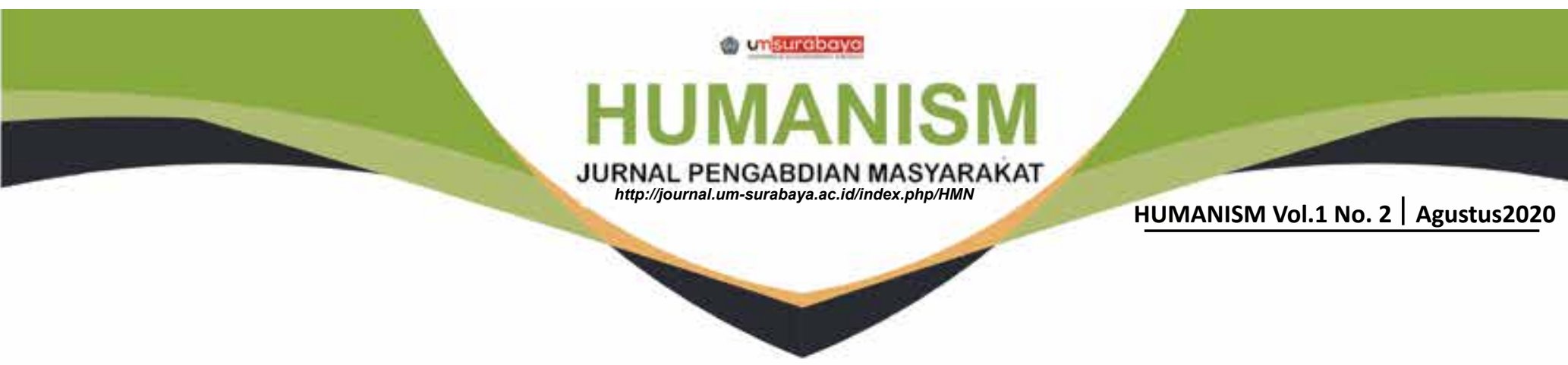

\title{
PENDAMPINGAN MOTIVASI PENINGKATAN KINERJA PENGURUS \\ DALAM PENGELOLAAN ORGANISASI DAN \\ INFORMASI TEKNOLOGI KOPERASI WANITA \\ DI KECAMATAN DRIYOREJO GRESIK
}

\author{
Endang Muryani ${ }^{1}$, Dwi Suhartini ${ }^{2}$, Alvien Gunawan ${ }^{3}$, \\ Rachman Halim Yustiyawan ${ }^{4}$, Yanna Eka Pratiwi ${ }^{5}$
}

${ }^{1}$ Prodi Manajemen Fakultas Ekonomi Universitas Merdeka Surabaya.

${ }^{2}$ Prodi Akuntansi Fakultas Ekonomi Universitas veteran Nasional Surabaya.

${ }^{3}$ Prodi Akuntansi Fakultas Ekonomi Universitas Ma'arif Hasyim Latif.

${ }^{4}$ Prodi Manajemen Sekolah Tinggi Ilmu Ekonomi IBMT.

${ }^{5}$ Prodi Akuntansi Fakultas Ekonomi Universitas Merdeka Surabaya.

emuryani56@gmail.com ${ }^{1}$

\begin{abstract}
Abstrak
Peningkatan motivasi pengurus dalam mengelolah koperasi khususnya koperasi wanita yang merupakan bentuk realisasi Program Gubernur Jawa Timur tahun 2010 merupakan faktor penting yang harus dilakukan dalam mengembangkan sumber daya manusia pengelola koperasi. Koperasi Wanita di wilayah kecamatan Driyorejo sebanyak 16 Koperasi Wanita yang merupakan bagian dari 355 koperasi wanita yang ada di kabupaten Gresik. Pendampingan dilakukan dengan metode motivasi, pelatihan intensif dan pengenalan serta pengoperasikan teknologi informasi terhadap pengelola koperasi wanita. Tujuan pendampingan untuk menstimulasi pengelola untuk tetap semangat dalam melaksanakan manajerial koperasi. Pendampingan dilakukan secara berkelanjutan disesuaikan dengan kondisi sumber daya manusia pengurus, mengingat pengurus berasal dari orang yang belum mempunyai latar belakang tentang perkoperasian. Hasil dari kegiatan pendampingan ada perubahan pemikiran dan perilaku pengelola atau pengurus dalam melaksanakan manajerial seperti yang pertama bidang organisasi melaksanakan pendidikan anggota yang bertujuan menambah wawasan tentang tanggung jawab sebagai anggota dan sekaligus sebagai regenerasi pengurus. Yang kedua pengelolaan akuntansi koperasi, mampu mengerjakan akuntansi koperasi dengan menggunakan Informasi Teknologi. Dengan menggunakan program tersebut berdampak pada proses laporan akuntansi lebih mudah dan menghasilkan suatu laporan keuangan secara sistematis sehingga laporan pertanggung jawaban pengurus pada anggota dapat dilaksanakan dengan tepat sesuai jadwal yang harus dilakukan sebagai koperasi primer.
\end{abstract}

Kata kunci : Motivasi, Kinerja Pengurus Koperasi Wanita, Informasi Teknologi. 


\section{PENDAHULUAN}

Kabupaten Gresik memiliki koperasi wanita hasil pencanangan program Gubernur pada tahun 2009 dimana program tersebut diprioritaskan untuk mengangkat peran kaum hawa dalam beraktualisasi berperan meningkatkan sumber daya manusia di bidang perekonomian melalui kegiatan kelompok perempuan dan berlanjut dengan terbentuknya suatu badan usaha yang diberi nama koperasi wanita. Organisasi koperasi dapat meningkatkan pembangunan perekonomian karena mampu mempersatukan, mengarahkan dan mengembangkan daya kreasi, daya cipta serta daya usaha rakyat, koperasi mempunyai kedudukan dan fungsi yang sama dengan badan-badan usaha milik negara atau swasta melakukan berbagai usaha demi tercapainya kesejahteraan masyarakat (Prihatini and Arief 2012).

\section{Di kabupaten Gresik memiliki 18} kecamatan dimana dua kecamatan berada di pulau Bawaean dimana setiap kecamatan memiliki 16 sampai dengan 26 desa, yang menarik di Gresik diantara delapan belas kecamatan ada dua kecamatan yang letaknya mencapai mencapai $152 \mathrm{~km}$ dari pelabuan Gresik dengan transpotasi jalur laut dan udara dengan penerbangan dua kali dalam satu minggu. Dari data tersebut setiap desa memiliki koperasi wanita sehingga jumlah koperasi berkisar 355 kopwan. Program kopwan yang ada di popinsi Jawa Timur merupakan program dari atas ke bawah dengan memberikan bantuan dana hibah, tujuan dibentuk koperasi dengan harapan mampu membangun dan mengembangkan potensi dan kemampuan ekonomi setiap anggota dan masyarakat untuk selalu meningkatkan dan mempertahankan kesejahteraan ekonomi masyarakat, mampu berperan serta secara aktif dalam upaya meningkatkan dan memperbaiki kualitas kehidupan manusia dan masyarakat, dan memperkokoh perekonomian rakyat sebagai dasar kekuatan dan ketahanan perekonomian nasional dengan koperasi sebagai soko guru, serta berusaha untuk mewujudkan dan mengembangkan perekonomian nasional, yang merupakan usaha bersama berdasarkan atas asas kekeluargaan dan demokrasi ekonomi.

Pembentukan koperasi ditujukan pada masyarakat yang ada di wilayah setiap desa meskipun wawasan pengurus ada yang awam dengan koperasi sehingga memerlukan berbagai pendampingan baik dari segi organisasi dan pengelolaan koperasi, serta beraneka ragam pendidikan yang di miliki oleh pengurus. Data pendidikan pengurus koperasi wanita yang ada di kecamatan Driyorejo dari :

Tabel 1. Data Anggota Koprasi

\begin{tabular}{|c|l|l|c|c|c|c|}
\hline \multirow{2}{*}{ NO. } & \multirow{2}{*}{ NAMA KOPWAN } & \multirow{2}{*}{ NAMA DESA } & \multicolumn{4}{|c|}{ PENDIDIKAN } \\
\cline { 5 - 7 } & & & SD & SMP & SMU & PT \\
\hline 1 & Artha Kencana & Cangkir & - & & 3 & 2 \\
\hline 2 & Sekar Melati & Sumput & & & 5 & \\
\hline 3 & Hasil Bunda & Randegansari & & & 4 & 1 \\
\hline 4 & Wanita Bermakna & Kesamben Wetan & & & 4 & 1 \\
\hline 5 & Maju Sejahtera & Wedoroanom & & 1 & 3 & 1 \\
\hline 6 & Bina Usaha & Karangandong & & & 3 & 2 \\
\hline 7 & Kartini & Gadung & & & 4 & 1 \\
\hline
\end{tabular}




\begin{tabular}{|c|l|l|c|c|c|c|}
\hline 8 & Sejati & Banjaran & & & 4 & 1 \\
\hline 9 & Mulyasari & Mulung & & & 3 & 2 \\
\hline 10 & Wanita Berkarya & Driyorejo & & & 4 & 1 \\
\hline 11 & Restu Ibu & Tenaru & & & 3 & 2 \\
\hline 12 & Siti Jenar & Bambe & & & 4 & 1 \\
\hline 13 & Usaha Ibu & Krikilan & & & 3 & 2 \\
\hline 14 & Manunggal Sejahtera & Petiken & & & 5 & \\
\hline 15 & Sekar & Tanjungan & & & 5 & \\
\hline
\end{tabular}

Berdasarkan data kecamatan yang terdiri dari 16 desa hanya ada 1 koperasi wanita yang ada di desa Mojosarirejo tidak tercantum karena koperasi tidak aktif dikarenakan ketidakmampuan pengurus dalam mengelola koperasi sehingga tidak dapat operasional. Sumber daya manusia merupakan modal utama dalam menjalankan sebuah organisasi koperasi yang akan berpengaruh terhadap kinerja koperasi sehingga diperlukan suatu motivasi untuk menstumulasi baik pengurus maupun anggota dalam kegiatan dapat tercapai sesuai yang diharapkan (Muryani dan Sanusi 2018). Koperasi seharusnya mengikuti perkembangan teknologi informasi, sehingga tidak tertinggal dalam pengembangan kegiatan usahanya. Dalam perkembangannya, banyak koperasi berhenti di tengah jalan karena kurang baiknya pengelolaan yang dilakukan oleh pengurusnya, di mana mereka menganggap bahwa koperasi hanya sebagai pekerjaan sambilan setelah menyelesaikan pekerjaan utama, akan tetapi banyak pula koperasi yang berkembang karena pengelolaan dilakukan secara professional (Setyawati et al. 2018). Untuk mendukung pengelolah tetap bersemangat dalam menjalankan tata kelola koperasi diperlukan suatu motivasi, karena motivasi merupakan tenaga atau faktor yang terdapat di dalam diri manusia, yang menimbulkan, mengarahkan dan mengorganisasikan terkait dengan perilaku (Muryani et al. 2018).
Selain koperasi memerlukan suatu motivasi juga memerlukan suatu pendampingan cara mengelola manajemen keuangan untuk mengelola keuangan yang efisien dan efektif dalam membuat laporan keuangan. Selain mempermudah dalam membuat laporan keuangan juga untuk mengevaluasi di internal organisasi itu sendiri. Kegiatan koperasi saat ini dalam pengawasan OJK (Otorisasi Jasa Keuangan) sehingga menjadi kewajiban sedini mungkin untuk mempersiapkan laporan keuangan secara profesional, seiring berkembangnya waktu akan diadakan audit internal yang hanya fokus pada masalah keuangan, audit internal pada saat ini juga mendukung manajemen organisasi untuk mencapai tujuannya dengan memanfaatkan sumber daya yang ada secara efisien dan meningkatkan bisnis serta proses manajemen risiko (Lastianti et al. n.d.)

\section{TINJAUAN PUSTAKA}

Teori motivasi ini merupakan dorongan yang ada di dalam diri manusia untuk meningkatkan prestasi. Menurut MC Clelland, individu dapat memiliki motivasi jika memang dirinya memiliki keinginan untuk berprestasi lebih baik. Kebutuhan prestasi yang tercermin dari rasa keinginan untuk melakukan sesuatu yang bisa dipertanggung jawabkan secara individu. 
Dengan menentukan menentukan tujuan yang diharapakan serta memperhitungkan resiko yang ada serta melakukannya secara kreatif dan inovatif (Muryani et al. 2018). Kebutuhan Afiliasi. kebutuhan Kekuasaan, kebutuhan ini dapat terlihat pada diri seseorang yang ingin memiliki pengaruh atas diri orang lain. Mereka haruslah peka terhadap struktur pengaruh antara satu sama lainnya, bahkan mencoba untuk menguasai orang tersebut hingga mengatur tingkah lakunya (Yustiyawan, Rachman Halim. 2016)

Kinerja secara harfiah kinerja adalah kata benda yang pengertiannya sama dengan hasil atau prestasi, kinerja dalam literatur manajemen dan organisasi memiliki makna yang lebih luas dan beragam; bukan sekedar hasil atau prestasi. Cermati misalnya pemahaman dan makna kinerja seperti yang dirangkum oleh Lebas \& Euske (2004) sebagai berikut.

1. Kinerja merupakan sesuatu yang dapat diukur, baik diukur menggunakan angka atau menggunakan sebuah ekspresi yang memungkinkan terjadinya komunikasi

2. Kinerja berarti berupaya, sesuai dengan maksud tertentu, untuk menghasilkan sesuatu (misal upaya menciptakan nilai)

3. Kinerja adalah hasil dari sebuah tindakan

4. Kinerja adalah kemampuan untuk menghasilkan atau potensi untuk menciptakan hasil (sebagai contoh, kepuasan pelanggan bisa dilihat sebagai potensi bagi organisasi untuk menciptakan penjualan di masa yang akan datang)

5. Kinerja adalah perbandingan antara hasil dengan benchmark (patokan) tertentu baik yang ditetapkan secara internal maupun patokan eksternal
6. Kinerja adalah hasil yang tidak diduga (mengejutkan) dibandingkan dengan yang diharapkan

7. Dalam disiplin psikologi, kinerja adalah bertindak (acting out)

8. Kinerja adalah pergelaran, khususnya dalam seni pertunjukan, yang melibatkan para aktor, peran mereka dan bagaimana peran dimainkan serta melibatkan orang luar yang menonton pergelaran tersebut.

9. Kinerja adalah judgment (sebuah keputusan atau penilaian) yang didasarkan pada sesuatu yang lain sebagai pembanding. Persoalannya adalah siapa yang harus menjadi pengambil keputusan dan bagaimana kriterianya (Sobirin 2014)

\section{METODE}

Kegiatan yang dilakukan dalam rangka pengabdian masyarakat untuk memotivasi pengelola koperasi wanita meningkatkan kinerja dengan dengan cara: Pendampingan dibidang pengelolaan organisasi koperasi seperti Standar Operasional Manajemen dan Standard Operasional Prosedur. Pengelolaan teknologi informasi dalam melaksanakan manajemen akuntansi koperasi. Adapun pembukaan dan kegiatan pendampingan dilaksanakan di Kantor Kecamatan Driyorejo jalan Tenaru Driyorejo kabupaten Gresik dilanjutkan di setiap kopwan di desa masing-masing.

\section{HASIL DAN PEMBAHASAN}

Koperasi wanita mampu melakukan perkembangan inovasi dalam mengoperasionalkan kegiatan manajerial organisasi sesuai dengan Standar Operasional Manajemen dan Standard Operasional Prosedur, sehingga menciptakan suasana keharmonisan antara pengurus dan anggota. Dengan adanya 
pembinaan dengan mingguan informasi teknologi mampu melaksanakan pengelolaan manajemen akuntansi sehingga menghasil laporan pertanggung jawab pengurus pada anggota tepat waktu sesuai jadwal koperasi primer pada umumnya. Kegiatan pengabdian masyarakat dihadiri oleh pengurus dari setiap koperasi.

Tabel 2. Daftar Kehadiran Peserta Pembinaan Dan Pendampingan

\begin{tabular}{|c|l|l|c|c|c|}
\hline \multirow{2}{*}{ NO. } & \multirow{2}{*}{ NAMA KOPWAN } & \multirow{2}{*}{ NAMA DESA } & \multicolumn{3}{|c|}{ KEHADIRAN } \\
\cline { 3 - 5 } & & JML & \multirow{2}{*}{ HADIR } & \multirow{2}{*}{ PENGURUS } \\
\hline 1 & Artha Kencana & Cangkir & 5 & 5 & 100 \\
\hline 2 & Sekar Melati & Sumput & 5 & 2 & 40 \\
\hline 3 & Hasil Bunda & Randegansari & 5 & 5 & 100 \\
\hline 4 & Wanita Bermakna & Kesamben Wetan & 5 & 3 & 60 \\
\hline 5 & Maju Sejahtera & Wedoroanom & 5 & 2 & 40 \\
\hline 6 & Bina Usaha & Karangandong & 5 & 4 & 80 \\
\hline 7 & Kartini & Gadung & 5 & 2 & 40 \\
\hline 8 & Sejati & Banjaran & 5 & 3 & 60 \\
\hline 9 & Mulyasari & Mulung & 5 & 3 & 60 \\
\hline 10 & Wanita Berkarya & Driyorejo & 5 & 3 & 60 \\
\hline 11 & Restu Ibu & Tenaru & 5 & 3 & 60 \\
\hline 12 & Siti Jenar & Bambe & 5 & 3 & 60 \\
\hline 13 & Usaha Ibu & Krikilan & 5 & 3 & 60 \\
\hline 14 & Manunggal Sejahtera & Petiken & 5 & 3 & 60 \\
\hline 15 & Sekar & Tanjungan & 5 & 3 & 60 \\
\hline & & & 75 & 47 & \\
\cline { 3 - 6 } & & & &
\end{tabular}
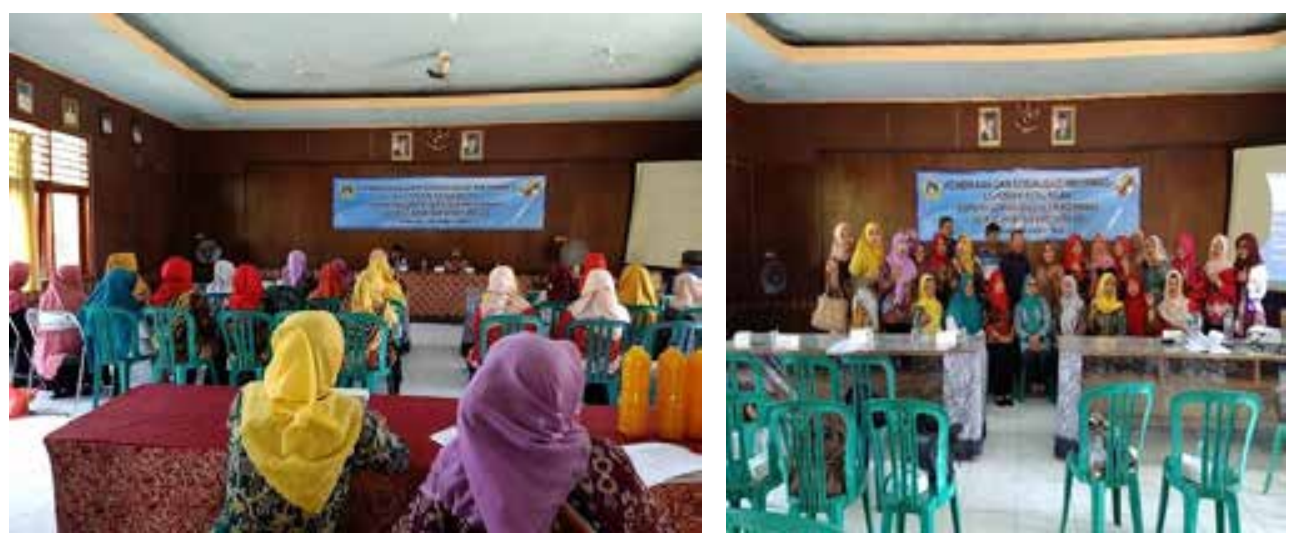

Gambar 1 Kegiatan Pembinaan Koprasi 

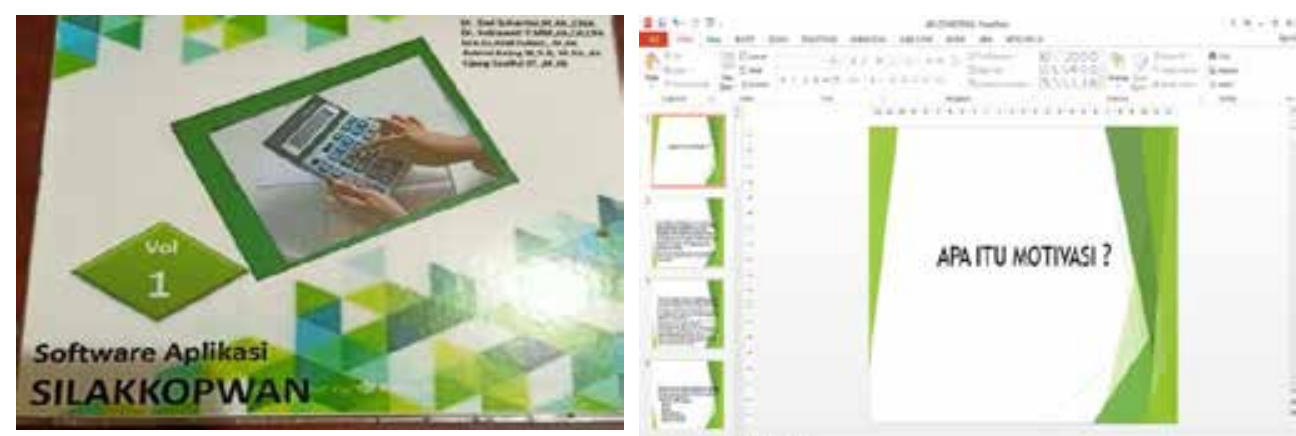

Gambar 2 Materi Pembinaan Koprasi

\section{KESIMPULAN}

Berdasarkan kegiatan pengabdian masyarakat yang telah dilakukan terhadap pengelola koperasi wanita yang berada di wilayah Kecamatan Driyorejo Gresik dapat disimpulkan sebagai berikut :

1. Mengoperasionalkan kegiatan manajerial organisasi sesuai dengan Standar Operasional Manajemen

2. Dalam pelayanan anggota sesuai dengan Standard Operasional Prosedur, sehingga menciptakan suasana keharmonisan antara pengurus dan anggota.

3. Dengan adanya pembinaan dengan menggunakan informasi teknologimampu melaksanakan Pengelolaan manajemen akuntansi sehingga menghasilkan laporan pertanggung jawab pengurus pada anggota tepat waktu sesuai jadwal koperasi primer pada umumnya.

\section{UCAPAN TERIMA KASIH}

Ucapan terimakasih yang sebesar-besarnya kami ucapkan kepada :

1. Ketua Yayasan dan Rektor Universitas Merdeka Surabaya yang telah mendukung dan mendanai Program Pengabdian Masyarakat yang bagian dari Tridharma Perguruan Tinggi.

2. Camat Driyorejo yang bersedia ketempatan diselenggarakan pembinaan dan pendampingan Koperasi Wanita se kecamatan.

\section{DAFTAR PUSTAKA}

Lastianti, Siwidyah Desi, Endang Muryani, MahrusAli, BayuAirlangga Putra, Hermien Tridayanti, Agus Sukoco, Yanna Ika Pratiwi, Supartini Supartini, Development Entrepreneurship, Intention Among, Meithiana Indrasari, Raditya Bambang Purnomo, Nur Syamsudin, Eddy Yunus, Web Based Application, Bayu Airlangga Putra, and Ani Wulandari. n.d. "The Role of The Internal Audit Management of Enterprise Risk Management." IJEBD 1 NO.2 Mar:110-19. 
Muryani, Endang, Alvien Gunawan, Zamri Bin Chik, Dedi Iskamto, and Putra Budi Ansori. 2018. "The Effect of Motivation on Performance at the Women's Cooperative Institute in Al - Barokah, Tuban Regency." International Journal of Academic Research in Business and Social Sciences 8(12):2136 - 2141.

Muryani, Endang and Anwar Sanusi. 2018. "Role Of Government , Ocb , Work Motivation, On Performance Of Women 's Cooperatives Through Participation Of Members In Gresik District.” 20(11):5969.

Prihatini, Tri and Ahmad Arief. 2012. "Analisis Pengaruh Motivasi Pengurus Dan Anggota Koperasi Terhadap Kinerja Koperasi (Studi Kasus Pada Koperasi Mahasiswa ABFII Perbanas)." Call Paper PEKAN ILMIAH DOSEN FEB - UKSW 73-86.
Setyawati, Irma, Sugeng Suroso, Delila Rambe, Prisila Damayanty, and Tyastuti Sri Lestari. 2018. "Upaya Peningkatan Pengelolaan Koperasi Simpan Pinjam Pada Sekolah Menengah Umum Di Kecamatan Jagakarsa." Jurnal Pengabdian Kepada Masyarakat UBJ 1(1):1-22.

Sobirin, Achmad. 2014. “Konsep Dasar Kinerja Dan Manajemen Kinerja." Manajemen Kinerja 1-67.

Yustiyawan, Rachman Halim. 2016. Hubungan Pengembangan Karir, Kompetensi Profesional, dan Motivasi dengan Kinerja Guru PAUD di Kecamatan Driyorejo Kabupaten Gresik. DISERTASI dan TESIS Program Pascasarjana UM 